\title{
HUSSERL E A HISTÓRIA \\ Sobre o "I m Zickzack Vor- und Zurückgehen", no § 9 da Crise das Ciências Europeias
}

\author{
Carlos Morujão \\ Universidade Católica Portuguesa
}

\section{A crítica do historicismo no Logos-Aufsatz.}

No artigo programático escrito, em 1911, para o n. 1 da revista Logos, intitulado A Filosofia como Ciência de Rigor, Husserl julga com severidade os efeitos da filosofia romântica em geral, e da filosofia de Hegel em particular, caracterizando-as como um "enfraquecimento ou falsificação do impulso para a constituição de uma ciência filosófica rigorosa." ${ }^{1}$ Cerca de vinte e cinco anos mais tarde, num dos muitos Apêndices que o editor do volume $\mathrm{VI}$ da Husserliana acrescentou ao texto do livro da Crise, Husserl reivindicava ainda a fidelidade ao ideal de ciência, e escrevia: "Sou um filósofo do meu tempo, do meu presente, no sentido em que trabalho e, nessa medida, ensino para nós todos em comunidade [...], sobre o solo da ciência universalmente válida deste tempo - no qual cresci interiormente pela educação e pela aprendizagem [...]."2 É, então, em nome de uma certa ideia

\footnotetext{
${ }^{1}$ Edmund Husserl, Philosophie als strenge Wissenschaft, in Husserliana, Band XXV, pp. 6-7. (De agora em diante, todas as nossas referências remetem para esta edição das obras de Husserl, identificada pela abreviatura Hua, publicada sob os auspícios dos Arquivos Husserl da Universidade de Lovaina. Indicaremos, somente, o volume, em algarismos romanos, e a paginação, em algarismos árabes.)

${ }^{2}$ Idem, Die Krisis der europäischen Wissenschaften und die transzendentale Phänomenologie, Beilage XXV, in Hua, Band VI, pp. 491 e segs., p. 492. (no seguimento, identificaremos esta obra pela abreviatura Krisis.) Seria inútil, todavia (pelo menos assim o pensamos), querer determinar a que ciência ao certo Husserl se refere. Estamos em querer que visa, em primeiro lugar, o ideal de ciência, que as ciências efectivamente existentes - as que se regem pelo
} 
de ciência, e da responsabilidade do pensar que se guia pelo ideal de ciência, que Husserl recusa o historicismo e a concepção da história que lhe é inerente.

Para o historicismo, enquanto fruto tardio daquela filosofia romântica, não pode haver uma filosofia científica, porque o mundo e a vida não são separáveis do pensamento que os pensa, e cada pensador encarna, somente, uma das múltiplas possibilidades históricas do viver e do pensar ${ }^{3}$. Em comsonância com esta ideia, Dilthey, numa carta a Husserl, de 29.06.1911, afirma que não são apenas os fracassos historicamente comprovados da filosofia em adquirir forma científica que obrigam a concluir que ela jamais o virá a conseguir, mas sim a relação geral entre as tarefas de uma filosofia científica e os meios humanos para as resolver. ${ }^{4} \mathrm{O}$ historicismo, para Husserl, significa uma submissão ao domínio dos factos, ao plano das razões históricas que originam, apenas, resultados históricos, a partir dos quais não podermos fundamentar ideias nem decidir sobre questões de valor. ${ }^{5}$ Mas, de factos, só podem resultar factos.

ideal de cientificidade que foi estabelecido pelos tempos modernos - reduziram a uma "generalidade fluida e indeterminada" (cf. Cartesianische Meditationen, § 3; in Cartesianische Meditationen und Pariser Vorträge, in Hua, Band I, p. 49), mas que a fenomenologia transcendental tem por missão reactivar.

3 Na realidade, tais possibilidades históricas são, para Dilthey, apenas três, embora se apresentem em configurações epocais diferenciadas: o naturalismo, o idealismo da liberdade e o idealismo objectivo. Acerca da necessidade de, a partir de uma perspectiva historicista, constituir tais tipologias, veja-se Odo Marquard, "Weltanschauungstypologie. Bemerkungen zu einer anthropologischen Denkform des neunzehnten und zwantigsten Jahrhunderte", in Schwierigkeiten mit der Geschichtsphilosophie, Frankfurt am Main, Suhrkamp Verlag, 1992, pp. 107-121.

${ }^{4}$ Edmund Husserl, Briefwechsel, Dordrecht / Boston / London, Kluwer Academic Publishers, 1994, Band VI, pp. 43-47.

${ }^{5}$ Sobre a distinção entre factos e essências, cf, I deen zu einer reinen Phänomenologie und phänomenologischen Philosophie (Ideen I), "Einleitung", in Hua, Band III, p. 6: “[...] aqui, fundar-se-á a fenomenologia pura ou transcendental, não como uma ciência de factos, mas sim como uma ciência de essências (como uma ciência "eidética"), como uma ciência que quer estabelecer exclusivamente a 'conhecimentos essenciais' e não, em absoluto, factos." 
Nesta perspectiva, o historicismo é inimigo da ciência. O seu perigo não é menor do que o do psicologismo naturalista, e conduz a análogas complicações cépticas. Se este último arruina a pretensão de verdade das proposições lógico-matemáticas, ao fazer depender o seu valor dos processos psíquicos reais que acompanham a sua formulação, já o historicismo acarreta a transformação de cada filosofia em mera realização cultural, motivada por circunstâncias históricas particulares e condenada a desaparecer no curso da evolução posterior da humanidade. ${ }^{6}$ A isto, como se sabe, Husserl contrapõe duas teses: em primeiro lugar, a da existência de valores "em si", que o seriam ainda que nenhuma humanidade histórica os realizasse; em segundo lugar, a da distinção entre o plano dos valores e o das realizações culturais, que se relacionam platonicamente, como diz o Logos-Aufsatz, como a ideia com a forma turva da sua manifestação. ${ }^{7}$

Dilthey, como sabemos, não se reconhecerá na visão que, do historicismo, Husserl apresenta em 1911, afirmando, inclusivamente, que é a própria realidade histórica, enquanto realização imperfeita das essências, que constrange a uma busca do sentido e das significações, capazes de ultrapassar o relativismo. Se, por um lado, a vida nos impele a reflectir sobre tudo aquilo que nela se dá, e se, por outro, a reflexão nos conduz à dúvida e ao cepticismo, é ainda a própria vida, defende Dilthey, que, opondo-se a ele, constrange o pensamento a alcançar um saber válido. Ou seja, num outro plano e motivado por outros interesses, o tema próprio do historicismo de Dilthey não nos parece opor-se radicalmente à análise intencional, tal como Husserl a pratica nas Investigações Lógicas e em Ideias I Trata-se, para ambos os autores, de fixar identidades, permanências de sentido, que permitam constituir um dado objecto como sendo esse mesmo objecto e não

\footnotetext{
${ }^{6}$ Philosophie als strenge Wissenschaft, in Hua, Band XXV, p. 43.

7 I bidem, p. 44: "A história, as ciências empíricas do espírito, nada podem decidir por si mesmas, nem num sentido positive nem num sentido negativo, sobre se se deve distinguir entre a religião como figura cultural e a religião como ideia, isto é, a religião autêntica, ou entre a arte como figura cultural e a arte autêntica, ou entre o direito histórico e o direito autêntico, ou entre a filosofia histórica e a filosofia autêntica; ou se entre eles, falando à meneira platónica, não existirá a relação da ideia com a forma turva da sua manifestação."
} 
outro. Veja-se, por exemplo, o texto seguinte, em que Dilthey parece reivindicar, não apenas os objectivos, mas, inclusivamente, a orientação metodológica da fenomenologia:

É trabalho constante do pensamento captar as relações existentes na consciência, dentro e em cada uma destas realidades da vida, e ascender do singular, contingente e acidental, que chegou, assim, a uma consciência clara e distinta, à conexão necessária e universal nele contida. (..) e a filosofia não é mais do que a energia máxima deste tornar consciente, como consciência acima de toda a consciência e saber acima de todo o saber. ${ }^{8}$

Contudo, para Husserl, historicismo e hegelianismo não se identificam, pura e simplesmente; o primeiro, de acordo com o Logos Aufsatz, é o segundo mal compreendido, ou seja, é o reconhecimento de que cada época tem a sua legitimidade própria, separado da concepção especulativa da história, que dá àquele reconhecimento um sentido não-relativista. Por isso, Hegel, que não perdera a crença na possibilidade de uma filosofia absoluta, define o presente como realização da história. Ora, quando, ao contrário de Hegel, Husserl define o presente como crise, ${ }^{9}$ tal resulta ainda de uma concepção da história determinada, já em 1911, não menos do que a de Hegel, embora de forma diferente, por considerações de ordem teleológica. Se crise existe, é porque a história e, em particular, a história europeia, não é uma mera história de factos, mas sim história que vive e progride na tensão motivada pela realização de uma finalidade. Ou, noutros termos, na linguagem das Investigações Lógicas, por uma intenção em busca de preenchimento.

\footnotetext{
${ }^{8}$ Cf. Wilhelm Dilthey, Der Aufbau der geschichtlichen Welt in den Geiteswissenschaften, in Gesammelte Werke, Band VII, Stuttgart, B. G. Teubner Verlagsgesellschaft / Göttingen, Vandenhoeck und Ruprecht, 1958, p. 7. Sobre a relação entre Husserl e Dilthey, pode consultar-se Jesús Díaz Álvarez, Husserl y la História, Madrid, Universidad Nacional de Educación a Distancia, 2003, pp. 103-11. Esta obra foi-nos amavelmente oferecida pelo autor, numa altura em que este ensaio, com excepção das notas de rodapé, se encontrava já, quanto ao essencial, redigido. Por este motivo, não podemos mais do que fazer-Ihe, aqui, esta curta referência.

${ }^{9}$ Sobre esta contraposição, cf. Paul Janssen, Geschichte und Lebenswelt, Den Haag, Martinus Nijhoff, 1970, pp. 119 e segs.
} 
É no contexto de tais considerações que se nos torna compreensível a crítica husserliana ao historicismo, esboçada no Logos-Aufsatz, entendido, não tanto como uma determinada prática de investigação do passado (como chegou a acontecer no quadro da escola histórica alemã do século XIX), como, antes, uma forma de pensar para a qual, uma vez que tudo o que parece fixo é apenas um momento na corrente da evolução, não é possível estabelecer unidades de valor objectivo.

\section{O sentido teleológico da História, em Husserl}

Tentemos reflectir sobre os problemas colocados por uma concepção teleológica da história, a partir daquela que é, possivelmente, a sua dificuldade mais imediata: que resposta tem uma tal concepção para a pergunta, que não pode deixar de colocar a si mesmo todo aquele que investiga o passado, sobre o que é que realmente aconteceu. A tal pergunta, poderíamos, ainda, acrescentar uma outra, que o historiador não necessita obrigatoriamente de fazer, mas que o filósofo, interrogando-se sobre o sentido do que aconteceu, pode colocar: será que o acontecido autoriza a que se fale de uma história? Esta última dificuldade fora já evidenciada por Kant, que, no ensaio intitulado I deias para uma História Universal numa Perspectiva Cosmopolita, a formula nos seguintes termos: "Uma vez que os homens, nos seus esforços, não se comportam de modo instintivo, como os animais, nem, todavia, como cidadãos racionais do mundo, de acordo com um plano acordado, parece não ser possível [ ...] uma história deles de acordo com um plano." ${ }^{10}$

Numa primeira abordagem, lendo este texto no horizonte do que poderíamos chamar uma concepção "estrutural" da fenomenologia, ${ }^{11}$ ou seja, da fenomenologia como investigação transcendental sobre a correlação entre os domínios de objectividade e a consciência de evidência, diríamos que ele aponta, simplesmente, para toda a problemática de constituição do "objecto"

\footnotetext{
${ }^{10}$ Kant, I deen zu einer allgemeinen Geschichte in Weltbürgerlicher Absicht, in Werke (hrsg. Von Wilhelm Weischedel), Darmstadt, Wissenschaftliche Buchgesellschaft, 1983, Band VI, p. 34 (A 388).

${ }^{11}$ Cf. J acques Derrida, “' 'Genèse et structure' et la phénoménologie”, in L 'Écriture et la Diférence, Paris, Éditions du Seuil, 1967, pp. 229-251, esp. pp. 248-249.
} 
história; de constituição, portanto, de uma ontologia regional, que teria também o seu lugar no seio dessa proto-região que é a consciência, após a efectuação do movimento da redução. Mas Kant coloca ainda aqui, mesmo se não o resolve, um problema de outra ordem, a saber, o da existência de elementos que, sendo explicáveis, até certo ponto, a partir de circunstâncias dadas anteriormente, não são, porém, totalmente passíveis de uma dedução a partir delas. Na linguagem da fenomenologia, o problema formular-se-á do seguinte modo: a história, se possui um eidos (e deverá possuí-lo, se é ainda uma região), não poderá ter um eidos à maneira do das diversas regiões do mundo, uma vez que os agentes históricos agem segundo normas e valores, ora no quadro de uma tradição, ora recusando-a e instituindo normas e valores de outro género. (De uma forma por ventura distorcida, não teria dado já conta desta situação a tipologia estabelecida por Dilthey, que anteriormente referimos?)

O aprofundamento de uma concepção do tempo histórico como a que se deixa adivinhar no texto de Kant, o reconhecimento do surgimento do novo e do diferente, e que dá ao tempo um carácter não-linear - a linearidade mais não é do que a projecção, no tempo, do que é próprio do espaço -, um tal aprofundamento, dizíamos, poderia ter constituído a contribuição própria da fenomenologia para o problema da história. O conhecido esquema do $\S 10$ das Lições sobre a Consciência do Tempo quebra o privilégio da concepção linear do tempo, enriquecendo-a, como diz Paul Ricoeur, em profundidade. A inadequação de uma simples concepção linear para a compreensão do tempo histórico era conhecida já pelos gregos, que tinham, no entanto, relativamente à história, uma sensibilidade bem diferente da nossa. Basta pensar, por exemplo, no famoso mito das idades do mundo, no Político de Platão. Além disso, a ideia de que os acontecimentos históricos fundamentais não se explicam a partir de circunstâncias dadas, que não se seguem delas, de acordo com a ordem linear do tempo físico, como um efeito se segue à sua causa, - o que não quer dizer, bem entendido, que pudessem ter sucedido se aquelas circunstâncias não se tivessem verificado -, parece exigida pela concepção husserliana da humanidade grega: com ela, irrompeu uma nova humanidade, fiel (nas palavras da Conferência de Viena de 1935) 
ao espírito de "livre crítica e livre normatividade", ou seja, não mais disposta a viver apenas segunda a tradição e, por isso mesmo, criadora da filosofia. Nenhuma espécie de causalidade explica satisfatoriamente que um tal tipo de humanidade possa ter irrompido. Husserl, em 1919, na conferência Natur und Geist ${ }^{12}$, recorre ao conceito de motivação como sendo o mais adequado para a compreensão de fenómenos desta natureza. O conceito será reelaborado nos $\S \S 54$ a 61 de Ideias $\mathrm{I}^{13}$, cuja redacção definitiva (pelo menos se a quisermos fazer corresponder à data em que o texto foi dactilografado) é um pouco posterior, devendo situar-se pelos anos 1924-25. Husserl distingue aí, na relação do Eu da intencionalidade com o seu Umwelt, uma relação de carácter intencional e outra de carácter real ou causal; a segunda deixa de ter lugar quando o objecto desaparece, ao passo que a primeira subsiste. A relação intencional com um objecto inexistente é, quanto a nós, aquela que caracteriza a humanidade histórica, nos momentos em que se decide a assumir o seu próprio futuro. Tal relação pode ser vista como uma modalidade da atitude do "como se" (consciência de "irrealidade", ou quase posicional), a que Husserl se refere no $\S 25$ das Meditações Cartesianas. ${ }^{14}$

É claro que, do ponto de vista de quem estuda os fenómenos históricos, a motivação terá de ser, como diz Husserl, ruckwärts gerichtet; mas, do ponto de vista dos agentes históricos, ela é, antes de mais, vorwärts gerichtet, é uma motivação activa e o seu princípio é o do desenvolvimento. Diz, a este propósito, a referida conferência de 1919:

[...] a essência fundamental da subjectividade é apenas ser e só poder ser na forma do desenvolvimento, cada nova situação e cada novo acto motiva,

\footnotetext{
12 Hua, XXV, pp. 316-324, p. 321.

13 Ideen zu einer reinen Phänomenologie und phänomenologischen Philosophie, Zweiter Buch, in Hua, Band IV, p. 215 e segs. Cf. a definição de motivação, na p. 216.

${ }^{14}$ Cf. Cartesianische Meditationen, in Hua, Band I, p. 94: “Deste último lado [i. e., da imaginação] surge um conceito novo e universal de possibilidade, onde se reiteram, de forma modificada, no aspecto da simples "concebibilidade" (na atitude do pensar "como se"), todos os modos de ser, a começar pela simples certeza de ser. [...] Assim, estabelece-se uma oposição correlativa entre os modos de consciência de posicionalidade e os modos de consciência de "quase-posicionalidade" [...]."
} 
necessariamente, uma transformação do sujeito: a contrapartida do átomo imóvel é a mónada viva, que se desenvolve incessantemente. ${ }^{15}$

Husserl, porém, não se satisfaz, apenas, com uma explicação desta natureza. Para que o surgimento da humanidade grega - para retomarmos o nosso exemplo de há pouco - não seja um acontecimento entre outros, mas sim uma verdadeira Urstiftung (fundação originária) da nossa história europeia; quer dizer, para que, com tal acontecimento, um tipo particular de humanidade não se tenha visto, somente, enredado numa história particular (in eine Geschichte vertrickt, para utilizarmos uma expressão retirada ao título de uma obra de WiIhelm Schapp); por outras palavras, para que a humanidade grega e o que foi por ela fundado tenha podido determinar o sentido da nossa história e o esteja ainda determinando; é necessário proceder à compreensão do seu sentido interno, para lá do seu carácter factual. Tal será a tarefa reservada à compreensão teleológica da história.

O nosso objectivo principal não é, obviamente, estabelecer um confronto entre Husserl e Hegel, a propósito desta questão (aliás, já realizado, entre outros por Paul Janssen em Geschichte und Lebenswelt), mas sim averiguar se o tipo de temporalidade que subjaz à teleologia, tal como Husserl a entende, se pode conciliar com aquela outra concepção do tempo histórico a que há pouco aludimos. Hegel, como sabemos, criou, para resolver um problema semelhante, o conceito de "astúcia da razão", de que em vão procuraríamos equivalente na concepção fenomenológica do tempo histórico. Hegel explica que o único Weltgeist se mantém idêntico a si mesmo através das suas múltiplas particularizações - a saber, cada Volksgeist -, de forma que os interesses egoístas dos povos e dos agentes históricos são anexados por si enquanto meios da sua própria realização. ${ }^{16}$ Aqui, a teleologia é solidária da afirmação de que a lógica do agir escapa às intenções conscientes dos agentes, que não agiram em vão na perspectiva do tempo histórico, mesmo quando, ou

\footnotetext{
15 “Natur und Geist”, in Hua, Band XXV, p. 322.

${ }^{16}$ Cf. G. W. Fr. Hegel, Vorlesungen über die Philosophie der Weltgeschichte, in Vorlesungen, Band 12, Hamburg, Felix Meiner Verlag, 1996, em particular pp. 59 e segs.
} 
sobretudo quando, viram a sua particularidade sacrificada a favor dos interesses da razão. ${ }^{17}$

Vejamos o que nos diz um pequeno excerto, retirado do livro da Crise. É irrelevante, para o nosso propósito, que este texto se refira a um problema particular do livro da Crise, a saber, o da relação entre a crise contemporânea das ciências europeias (o texto, recordemo-lo, foi escrito em 1936) e o momento fundador da concepção moderna do mundo, levado a cabo por Galileu, no plano das ciências físico-matemáticas, e por Descartes, no plano da filosofia. O que aqui nos interessa são os aspectos metodológicos postos em relevo.

Encontramo-nos [...] numa espécie de círculo. A compreensão do começo só se pode obter completamente a partir da ciência dada na sua configuração actual, num olhar retrospectivo sobre o seu desenvolvimento. Mas sem uma compreensão dos começos, este desenvolvimento, como desenvolvimento do sentido, permanece mudo. Não nos resta senão o seguinte: devemos proceder em 'zigzag', para trás e para diante: num jogo recíproco, um [movimento] deve ajudar o outro. Uma relativa clarificação num dos lados traz esclarecimento para o outro, o qual, pelo seu lado, ilumina retrospectivamente o primeiro. Assim, ao jeito de consideração e de crítica históricas, que, partindo de Galileu (e, logo de seguida, de Descartes) tem de acompanhar o decurso do tempo, somos obrigados a fazer frequentemente saltos históricos, que não são, por conseguinte, divagações, mas sim necessidades. Necessidades quando nós, como foi dito, tomamos sobre a nós aquela tarefa de auto-reflexão, que surgiu da situação de 'desmoronamento' do nosso tempo, com o seu 'desmoronamento' da própria 'ciência'. ${ }^{18}$

Será então o procedimento em zig-zag que substituirá a filosofia especulativa da história, conservando desta, contudo, o sentido teleológico, já não enquanto conceito metafísico, mas sim como conceito que se revela de forma concreta na história, que é passível de ser lido no fenómeno histórico, no qual a sua estrutura se manifesta originariamente. ${ }^{19}$ Este procedimento, contudo, assenta em alguns pressupostos que tentaremos aqui explicitar e que afastam o método husserliano de qualquer relação com o círculo

\footnotetext{
17 Paul Ricoeur, Temps et Récit, Paris, Éditions du Seuil, 1985, vol. 3.o , pp. 355-356.

${ }^{18}$ Edmund Husserl, Krisis, § 9, I, in Hua, Band VI, p. 59.

${ }^{19}$ Alexandre F. Morujão, "A reflexão sobre a história na fenomenologia de Husserl", in Estudos Filosóficos, Lisboa, IN-CM, 2002, vol. I, pp. 399-435, p. 421.
} 
hermenêutico, ou círculo da compreensão, tal como Dilthey, por exemplo, o praticou, apesar de pontos de contacto interessantes e que agora não iremos explorar. (Mas que se podem detectar, por exemplo, a partir da leitura do $\S$ 56 f) de Ideias I, intitulado "Consciência natural e motivação"). ${ }^{20} \mathrm{O}$ primeiro deles, é que qualquer momento fundador (o momento do que Husserl chama a Urstiftung, no livro da Crise) é afectado por uma falta de clareza intrínseca, relativamente ao alcance do seu gesto inaugural. Não se trata de uma afirmação trivial, mas sim de algo que poderíamos classificar como estruturante da concepção husserliana da história. É assim que, em coerência com esta tese, Husserl afirma, por exemplo, que a novidade radical que consistiu na descoberta da subjectividade, por Descartes, ${ }^{21}$ foi acompanhada do desconhecimento do sentido do ego cogito, enquanto campo imanente de experiências fenomenológicas, e da sua compreensão a partir da noção tradicional, não criticada, de res ou substância. O segundo pressuposto é que tal falta de clareza afecta também, e sobremaneira, os que se reclamam da herança do momento fundador, ${ }^{22}$ de modo que a história se transforma num largo movimento de esquecimento e de decadência, até que o gesto inaugural seja, de novo, numa Nachstiftung, restituído à sua grandiosidade. A história caracteriza-se por permanentes modificações ou deslocações de sentido - Sinnverschiebungen como diz o § 9 da Krisis -, que aqueles que se encontram sob o fascínio de um qualquer momento fundador não conseguem captar. É assim que, prossegue Husserl, as ciências físicomatemáticas e os efeitos de ordem técnica que delas resultam se tornaram tão evidentes que já não entendemos mais o que a matemática significa, ou o que são as ciências da natureza. É este, quanto a nós, o sentido profundo do zig-zag husserliano: só o presente esclarece o sentido do passado que o possibilita.

\footnotetext{
${ }^{20}$ Hua, Band IV, pp. 229-23 1

${ }^{21}$ Cf. Krisis, § 16, Hua, Band VI, pp. 74-76.

22 Sobre a posteridade de Descartes, cf., por exemplo, "Telelologie in der Philosophiegeschichte", in Hua, Band XXIX, p. 400: "[...] nada foi feito com a tratamento da egoidade por Descartes e pela modernidade que dele saiu, e a ciência - seja qual for a esfera da humanidade - é uma tarefa, e uma tarefa não preenchida, por falta de clareza e por equívoco, pela ciência resultante."
} 
Este procedimento talvez se pudesse caracterizar pelas palavras com que Husserl, num texto que o editor do volume VI da Husserliana colocou como Apêndice ao livro da Crise, caracteriza a sua atitude global para com a história: "um wissenschaftliche Geschichtlichkeit unbekümmert", ou seja, "indiferente à historicidade científica". É uma espécie de história romanceada ou ficcionada, inesperada num pensador que jamais abandonou o ideal de cientificidade e de rigor filosóficos, mas, contudo, essencial para que ele próprio pudesse situar o seu empreendimento científico, simultaneamente, perante o passado e perante a crise do presente.

Há uma interessante discussão deste assunto num ensaio de Rudolf Boehm sobre a filosofia da história em Husserl, inserido numa recolha de estudos sobre Husserl intitulada Vom Gesichtspunkt der Phänomenologie. ${ }^{23}$ Boehm defende que a construção teleológica da história, levada a cabo por Husserl, não é, nem verdadeira, nem falsa. É uma pura descrição do modo como a história pode aparecer à consciência, levada a cabo sem a preocupação de correspondência com o mundo histórico verdadeiro, aliás, segundo o autor, impossível de restituir, da qual Husserl necessitava para poder realizar o seu empreendimento de fundação de uma filosofia fenomenológica. Boehm coloca este empreendimento husserliano sob o signo da crítica de Nietzsche ao "mundo verdadeiro", em O Crepúsculo dos Ídolos, mas a referência a Nietzsche parece-nos desnecessária. Já no Logos-Aufsatz, onde, no entanto, distinguira tão claramente a filosofia ideológica (presa às necessidades de uma época) e a filosofia científica (cujas proposições são verdadeiras sub specie aeternitatis), Husserl reconhece a necessidade de promover, por meios não científicos, a ideia de ciência.

Mas, então, uma vez que uma promoção da ciência por meios não científicos é possível e necessária, não se poderia perguntar a Husserl se a decisão pela ciência não teria, igualmente, um carácter não científico? Ou, por outras palavras, se não será esta opção tão legítima - tão racional ou tão irracional, conforme os pontos de vista - quanto a sua contrária? Pensamos que a resposta de Husserl seria negativa, e que a justificaria recorrendo, uma vez

${ }^{23}$ Rudolf Boehm, "Husserl und Nietzsche", in Vom Gesichtspunkt der Phänomenologie, Den Haag, Martinus Nijhoff, 1968, pp. 217-236, pp. 222 e segs. 
mais, à teleologia da Europa e da razão ocidental. ${ }^{24}$ (A discussão pormenorizada desta problemática terá de ser objecto de outro trabalho.)

\section{Tradição e inovação. Limites da concepção husserliana de história}

Se a história pode ser pensada teleologicamente, o modo de ser do que acontece releva uma estrutura temporal imanente. O sentido do acontecimento exprime-se na síntese entre o que ele é, o que ele foi e o que ele virá a ser. Não se trata, porém, de tempo em sentido habitual. É quase inevitável recordarmo-nos, a este propósito, da célebre definição que dele dá Aristóteles, no Livro III da Física: ${ }^{25}$ kai tóte phamen gegonénai chronon, hotan tou protérou kai hystérou en te kinései, aísthesin lábomen; dizemos que o tempo passou quando temos a sensação do anterior e do posterior no movimento. Voltaremos mais adiante a esta questão, pelas óbvias relações entre esta definição e a definição aristotélica do movimento, de que iremos ter necessidade no final desta comunicação. Husserl di-lo claramente, no $\S 15$ do livro da Crise, de que transcrevemos o seguinte excerto:

Trata-se, para nós, de tornar compreensível a teleologia no devir histórico da filosofia, em particular na moderna, e, juntamente com isso, tornar para nós claro o que nós próprios somos, como seus suportes, como aqueles que contribuem para a sua realização, na nossa deliberação pessoal. Procuramos captar a unidade que domina em todas as fixações de objectivos, na oposição e na colaboração que acompanham as suas transformações, e, por fim - numa crítica permanente, que tem sempre diante dos olhos, apenas, a conexão histórica total como algo de pessoal -, observar a tarefa histórica que podemos reconhecer como a única que nos é pessoalmente própria. Uma observação feita, não a partir de fora, do facto, como se o devir histórico, no qual nós próprios deviemos, fosse uma mera sucessão causal externa, mas sim a partir de dentro. [...]

Abramos aqui um curto parêntesis, antes de concluir a leitura deste excerto. Este enraizamento do tempo e do movimento na nossa própria natureza, que Husserl aqui exprime, parece-nos corresponder ao que há

\footnotetext{
24 Paul Janssen, op. cit., p. 121.

${ }^{25}$ Aristóteles, Física, III, 201 a 9.
} 
de mais profundo na concepção aristotélica sobre este assunto. O “de dentro" está em itálico no original. Encerramos o parêntesis e concluímos a leitura.

[...] Nós, que não temos apenas uma herança espiritual, mas que não somos outra coisa, de princípio ao fim, senão algo que deveio históricoespiritualmente, temos apenas uma tarefa verdadeira e própria. Não a ganhamos pela crítica de qualquer sistema presente ou transmitido do passado, de uma "visão do mundo" científica ou pré-científica (por fim, até de uma chinesa), mas apenas a partir de uma compreensão crítica da totalidade da história: da nossa história. ${ }^{26}$

Encontram-se, neste texto, quase todos os elementos que, segundo Husserl, caracterizam a história transcendental do eu, ou seja, a génese egológica, na qual se realiza o fenómeno de pertença a uma tradição. Por um lado, a série regular de experiências que constitui a unidade pessoal de um comportamento, em que todas as funções activas de síntese se submetem à forma constante e universal da temporalidade, que se constitui a si mesma numa génese contínua, passiva e universal. ${ }^{27}$ Podemos encontrar este processo abreviadamente explicitado nos $\S \S 38$ e 39 das Meditações Cartesianas. Por outro lado, a compreensão comunitária recíproca - tanto no plano sincrónico como diacrónico - , que institui uma concordância comportamental de carácter supra-pessoal ${ }^{28}$ (Husserl chama-Ihe eine verbundene Habitualität, um conjunto de hábitos ligados entre si). ${ }^{29}$ Esta elucidação dos problemas relativos à constituição da intersubjectividade é fundamental para a compreensão da génese do mundo histórico. Não há história sem o que Husserl chama a "penetração irreal", a "penetração intencional", 30 do outro na esfera primordial do ego. Falta apenas aqui a teoria, desenvolvida mais pormenorizadamente em A Origem da Geometria, da transformação da evidência originária em fluxo permanente, a degenerescência do presente

\footnotetext{
${ }^{26}$ Edmund Husserl, Krisis, § 15, in Hua, Band VI, pp. 71-72.

${ }^{27}$ Alexandre F. Morujão, art. cit., loc. cit., p. 408.

${ }^{28}$ Cf. Karl-Heinz Lembeck, Gegenstand Geschichte, Dordrecht / Boston / London, Kluwer Academic Press, 1988, pp. 155-156, bem como todos os textos de Husserl para os quais o autor remete nestas páginas.

${ }^{29}$ Zur Phänomenologie der Intersubj ektivität, in Hua, Band XV, p. 479.

${ }^{30}$ Cartesianische Meditationen, Hua, Band I, § 56.
} 
vivo num soebengewesensein - em algo que acabou justamente de $\operatorname{ser}^{31}$-, na passividade de uma retenção que exigirá a Wiedererinnerung. A relação com as análises da consciência íntima do tempo, em particular as análises da continuidade de um som no fenómeno do seu progressivo afastamento e obscurecimento, ${ }^{32}$ é demasiado evidente para que seja necessário insistirmos aqui nela.

Mas é, justamente, este conceito de Wiedererinnerung que nos parece problemático se aplicado ao decurso do tempo histórico. É certo que Husserl parece apenas visar a reiteração de uma idealidade (por exemplo, a geometria euclidiana), pela articulação de uma actividade de engendramento (Erzeugung) com a evidência originária. Mas a história efectiva não é a da reiteração de idealidades. Em Husserl, tudo como que se passa ao contrário: é a passividade das retenções que interrompe uma continuidade que a Wiedererinnerung tem por função restabelecer, ${ }^{33}$ envolvendo o presente e a origem numa mesma idealidade intemporal. Ou, talvez mais exactamente, a Wiedererinnerung quebra a continuidade da tradição - e do esquecimento da Urstiftung que a caracteriza -, restabelecendo uma outra continuidade, aquela, justamente, que, para lá das diferenças epocais, subsiste como razão desperta para as suas tarefas infinitas.

Este é o nervo da questão. Será que a geometria não-euclideana, por exemplo, reitera a de Euclides, mesmo admitindo que a possibilidade de uma geometria para um espaço a n dimensões estava, de certa forma, contida no discutido Axioma das Paralelas dos Elementos de Geometria? Não será, antes, necessário, não recordar iterativamente o momento de fundação do espaço euclideano, plano e tridimensional, mas sim inventar um espaço a mais de três dimensões para que as discussões sobre tal Axioma originem uma nova geometria? Husserl soube reconhecer a descontinuidade das fases de presença, na passividade da retenção. Com isso, levou ao seu termo, na análise do tempo, o método fenomenológico que consiste em desconectar o fluxo imanente da consciência, do curso objectivo do mundo e do

\footnotetext{
${ }^{31}$ Krisis, Hua, Band VI, p. 370.

32 Zur Phänomenologie des inneren Zeitbewusstseins, in Hua, Band X, p. 26.

33 Karl-Heinz Lembeck, op. cit., p. 165.
} 
tempo físico que o rege. O carácter sucessivo, contínuo, múltiplo, do primeiro, pode, assim, ser analisado sem a interferência do segundo e da crença que o acompanha. Se aplicarmos o conceito de Wiedererinnerung à compreensão do tempo histórico, teremos de admitir que o seu significado só poderá ser: algo persiste modificando-se. Ora, o conceito de motivação, que anteriormente referimos, não apontará para um outro tipo de compreensão do tempo histórico, para lá do recurso à teleologia e à Wiedererinnerung? Husserl escreveu, em Ideias I: “A pergunta do historiador é: que é que os membros da socialidade, na sua vida comunitária, representaram, pensaram, valorizaram, quiseram, etc. Como é que estes homens se 'determinaram' uns aos outros e se deixaram determinar pelo mundo de coisas que os circundava, como é que, pelo seu lado, agindo em retorno, o configuraram, etc." ${ }^{34}$ Agimos em retorno sobre o que nos circunda, configurando-o, e temos, então, a sensação de que o tempo passou. Aristóteles escrevia no Livro IV da Física ${ }^{35}$ : he tou dynámei ontos entelécheia he toiouton, kinésis éstin; o movimento é a enteléquia da coisa que existe em potência, enquanto existe em potência. O verdadeiro tempo histórico, tem, então, esta natureza: algo se modifica.

\section{Bibliografia}

ÁLVAREZ, Jesús Díaz, Husserl y la Historia, Madrid, Universidad Nacional de Educación a Distancia, 2003.

BOEHM, Rudolf, “Husserl und Nietzsche”, in Vom Gesichtspunkt der Phänomenologie, Den Haag, Martinus Nijhoff, 1968.

DERRI DA, Jacques, “'Genèse et structure' et la phénoménologie”, in L 'Écriture et la Diférence, Paris, Éditions du Seuil, 1967, pp. 229-251.

DILTHEY, Wilhelm, Der Aufbau der geschichtlichen Welt in den Geiteswissenschaften, in Gesammelte Werke, Band VII, Stuttgart, B. G. Teubner Verlagsgesellschaft / Göttingen, Vandenhoeck und Ruprecht, 1958.

HEGEL, G. W. Fr., Vorlesungen über die Philosophie der Weltgeschichte, in Vorlesungen, Band 12, Hamburg, Felix Meiner Verlag, 1996.

\footnotetext{
${ }^{34}$ Hua, IV, p. 229.

${ }^{35}$ Aristóteles, Física, IV, 219 a 22.
} 
HUSSERL, Edmund, Cartesianische Meditationen, in Cartesianische Meditationen und Pariser Vorträge, Husserliana, Band I, Den Haag, Martinus Nijhoff, 1963.

- Ideen zu einer reinen Phänomenologie und phänomenologischen Philosophie, Erstes Buch, in Husserliana, Band III, Den Haag, Martinus Nijhoff, 1976.

- Ideen zu einer reinen Phänomenologie und phänomenologischen Philosophie, Zweites Buch, in Husserliana, Band IV, Den Haag, Martinus Nijhoff, 1952.

- Die Krisis der europäischen Wissenschaften und die transzendentale Phänomenologie, in Husserliana, Band VI, Den Haag, Martinus Nijhoff, 1962.

- "Philosophie als strenge Wissenschaft", in Aufsätze und Vorträge, Husserliana, Band XXV, Dordrecht /Boston / London, Kluwer Academic Press, 1987.

- Zur Phänomenologie der Intersubj ektivität, Dritter Teil, in Husserliana, Band XV, Den Haag, Martinus Nijhoff, 1973.

- "Natur und Geist", in Husserliana, Band XXV, Dordrecht /Boston / London, Kluwer Academic Press, 1987, pp. 316-324.

- "Telelologie in der Philosophiegeschichte", in Die Krisis der europäischen Wissenschsften und die transzendentale Phänomenologie, Ergänzungsband, Husserliana, Band XXIX, Dordrecht / Boston / London, Kluwer Academic Press, 1993.

- Briefwechsel, Dordrecht / Boston / London, Kluwer Academic Publishers, 1994, Band VI.

JANSSEN, Paul, Geschichte und Lebenswelt, Den Haag, Martinus Nijhoff, 1970.

KANT, Ideen zu einer allgemeinen Geschichte in Weltbürgerlicher Absicht, in Werke, (hrsg. Von Wilhelm Weischedel), Darmstadt, Wissenschaftliche Buchgesellschaft, 1983, Band VI.

LEMBECK, Karl-Heinz, Gegenstand Geschichte, Dordrecht / Boston / London, Kluwer Academic Press, 1988.

MARQUARD, Odo, “Weltanschauungstypologie. Bemerkungen zu einer anthropologischen Denkform des neunzehnten und zwantigsten Jahrhunderte", in Schwierigkeiten mit der Geschichtsphilosophie, Frankfurt am Main, Suhrkamp Verlag, 1992

MORUJ ÃO, Alexandre F., "A reflexão sobre a história na fenomenologia de Husserl", in Estudos Filosóficos, Lisboa, IN-CM, 2002, vol. I, pp. 399-435.

RICOEUR, Paul, Temps et Récit, Paris, Éditions du Seuil, 1985, 3 vols. 


\begin{abstract}
O presente ensaio procura compreender a concepção husserliana da história a partir de conceitos tais como Urstiftung, Wiedererinnerung e Nachstiftung. Tentar-se-á, não só perceber as razões subjacentes à concepção teleológica da história, presente no livro da Crise (e nos textos que Ihe andam associados) e na Conferência de Viena de 1935, bem como o tipo de concepção do tempo histórico que é correlativa dela, mas também, sobretudo, detectar a possibilidade - a partir dos textos mesmos de Husserl - de uma outra concepção, mais apta a exprimir a novidade e a contingência.
\end{abstract}

